Case Report

\title{
Extreme Insulin Resistance in a Patient with Diabetes Ketoacidosis and Acute Myocardial Infarction
}

\author{
Yin H. Oo, ${ }^{1}$ Jocelyne G. Karam, ${ }^{1,2}$ and Christine A. Resta ${ }^{2}$ \\ ${ }^{1}$ Division of Endocrinology, SUNY Downstate Medical Center, Brooklyn, NY 11203, USA \\ ${ }^{2}$ Division of Endocrinology, Maimonides Medical Center, Brooklyn, NY 11219, USA \\ Correspondence should be addressed to Yin H. Oo; yin.oo@downstate.edu
}

Received 21 November 2012; Accepted 12 December 2012

Academic Editors: O. Isozaki, W. V. Moore, and R. Murray

Copyright (C) 2013 Yin H. Oo et al. This is an open access article distributed under the Creative Commons Attribution License, which permits unrestricted use, distribution, and reproduction in any medium, provided the original work is properly cited.

\begin{abstract}
Hyperglycemia is common in hospitalized patients and associated with adverse clinical outcomes. In hospitalized patients, multiple factors contribute to hyperglycemia, such as underlying medical conditions, pathophysiological stress, and medications. The development of transient insulin resistance is a known cause of hyperglycemia in both diabetic and nondiabetic patients. Though physicians are familiar with common diseases that are known to be associated with insulin resistance, the majority of us rarely come across a case of extreme insulin resistance. Here, we report a case of prolonged course of extreme insulin resistance in a patient admitted with diabetic ketoacidosis (DKA) and acute myocardial infarction (MI). The main purpose of this paper is to review the literature to identify the underlying mechanisms of extreme insulin resistance in a patient with DKA and MI. We will also briefly discuss the different clinical conditions that are associated with insulin resistance and a general approach to a patient with severe insulin resistance.
\end{abstract}

\section{Introduction}

In hospitalized patients, the development of transient insulin resistance related to different medical conditions such as acute myocardial infarction (MI), sepsis, and medications has been reported. However, the majority of us rarely come across a case of extreme insulin resistance. Here, we report a case of extreme insulin resistance in a patient admitted with diabetic ketoacidosis (DKA) and MI. To the best of our knowledge, our case is the second case report of extreme insulin resistance in a patient presenting with DKA and MI [1].

\section{Case Presentation}

A 60-year-old Hispanic man with a twenty-year history of type 2 diabetes mellitus presented with 2-day history of generalized weakness and dizziness with home glucose meter reading "High." Prior to this admission, he was on insulin glargine 20 units subcutaneously at bedtime and replaglinide $1 \mathrm{mg}$ oral three times per day. His fasting blood glucose level at home ranged from 100 to $200 \mathrm{mg} / \mathrm{dL}$. The admission hemoglobin A1c was $8.8 \%$. His past medical history includes hypertension, peripheral vascular disease, dyslipidemia, recent ischemic CVA, and a history of the left 4th and 5th toe amputations for osteomyelitis. Review of systems was essentially negative without chest pain, shortness of breath, fever, cough, dysuria, polyuria, or polydipsia. On exam, vital signs were unremarkable. Weight was $65 \mathrm{~kg}$ and body mass index (BMI) was 25 . Waist circumference was at $110 \mathrm{~cm}$. Apart from old right facial drop and ptosis, physical exam was also unremarkable.

Admission blood work revealed blood glucose of $847 \mathrm{mg} / \mathrm{dL}$ with serum bicarbonate of $15 \mathrm{mmol} / \mathrm{L}$, anion gap of $20, \mathrm{pH}$ of 7.28 , sodium of $120 \mathrm{mmol} / \mathrm{L}$ with serum osmolality of $321 \mathrm{mOsmol} / \mathrm{kg}$, and small serum acetone. $\mathrm{He}$ was also noted to have acute on chronic renal failure with creatinine of $3.3 \mathrm{mg} / \mathrm{dL}$ from baseline creatinine of $1.3 \mathrm{mg} / \mathrm{dL}$. EKG did not show any ischemic changes but initial cardiac troponin was $1.35 \mathrm{ng} / \mathrm{mL}$ which increased up to $>50 \mathrm{ng} / \mathrm{mL}$ subsequently. He was treated with IVF and regular insulin infusion as per our institution's DKA protocol. For non-ST elevation myocardial infarction (NSTEMI), he was treated medically. The anion gap was 


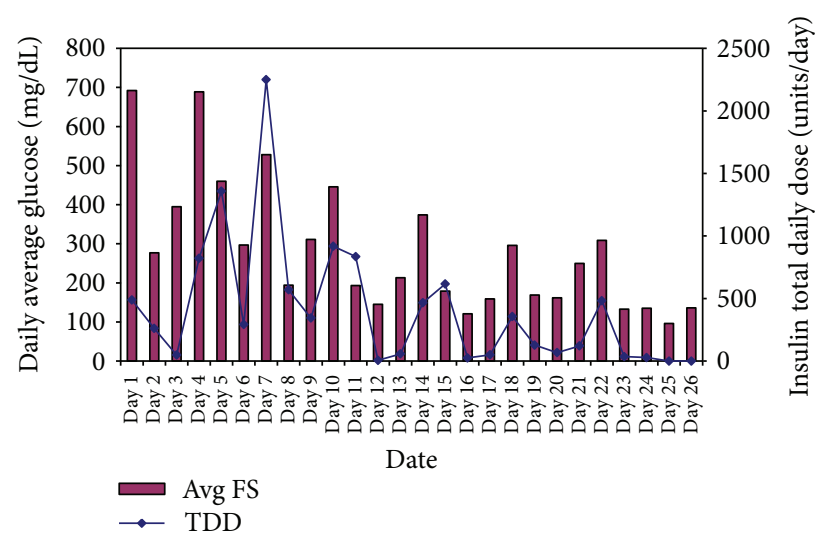

FIGURE 1: Daily average fingerstick (FS) blood glucoses in $\mathrm{mg} / \mathrm{dl}$ and insulin total daily dose (TDD) in units/day.

closed after receiving 657 units of regular insulin over 24 hour. By day 2, the anion gap closed and fingerstick blood glucoses ranged from 180 to $250 \mathrm{mg} / \mathrm{dL}$; he was given 20 units of subcutaneous glargine insulin. Four hours later, the insulin drip was stopped.

On day 3, he was again noted to have DKA with $\mathrm{pH}$ of 7.24, random blood glucose of $650 \mathrm{mg} / \mathrm{dL}$ with anion gap of 24. Regular insulin infusion per DKA protocol was restarted; however, fingerstick glucoses remained at "High" to $500 \mathrm{~s} \mathrm{mg} / \mathrm{dL}$ even with an insulin drip at a rate of 76 units/hour from day 3-4. There were no features of recurrent ischemia or concomitant infection. He was clinically and hemodynamically stable at all times. The levels of fingerstick glucoses and insulin requirements in the rest of hospital stay are summarized in Figure 1.

From day 5 to day 10, his insulin requirements varied from 120 units per hour to 1 unit per hour. Even though his anion gap was normal on day 5 , intravenous insulin infusion was continued as his insulin requirements were unpredictable with fluctuating blood glucose levels. There was no pattern to the blood glucose fluctuations. Possibilities of technical, human, or medication errors, occult infection, and recurrent ischemia were examined and excluded. Clinically, he did not have features of Cushing's syndrome, acromegaly, hyperthyroidism, lipodystrophy, acanthosis nigricans, autoimmune diseases, or hematological malignancy. Results of a workup for possible causes of extreme insulin resistance are summarized in Table 1. They were unremarkable apart from glucagon and cortisol, which are elevated within the physiologic range. Insulin autoantibodies are positive.

He had coronary artery bypass graft (CABG) on day 25 after coronary angiogram showed triple vessel coronary artery disease. Although we expected him to have increased insulin requirement in the perioperative period of CABG, in fact the insulin requirements and fluctuations in blood glucoses were significantly improved after CABG. He was not even on basal insulin because of the development of fasting hypoglycemia with a small amount of insulin glargine.

As he was having mainly post prandial hyperglycemia after CABG, he was discharged home with subcutaneous liraglutide $1.2 \mathrm{mg}$ daily and premeal insulin aspart 15 units tid. At 6-month followup, his fingerstick glucoses were reported in the range of $60-140 \mathrm{mg} / \mathrm{dL}$ with hemoglobin A1c of $6.6 \%$ on liraglutide and insulin aspart.

\section{Review on Insulin Resistance}

3.1. Definition. Insulin resistance has been broadly defined as "a state (of a cell, tissue, or organism) in which a greater than normal amount of insulin is required to elicit a quantitatively normal response" [2]. As per ADA consensus, it is a state of impaired insulin-stimulated glucose disposal as measured by the hyperinsulinemic-euglycemic clamp technique. Severe insulin resistance should be suspected when an individual requires more than 2 units $/ \mathrm{kg} /$ day of insulin. Extreme insulin resistance is a condition where an individual insulin requirement is more than 3 units $/ \mathrm{kg} /$ day [3]. Insulin resistance can be assessed by measuring insulin level at fasting or assessing the peak level of insulin achieved after oral glucose tolerance test (OGTT). Normal individuals generally have fasting serum insulin levels below $20 \mu \mathrm{U} / \mathrm{mL}$ or peak post-OGTT insulin levels less than $150 \mu \mathrm{U} / \mathrm{mL}$. Severe insulin resistance should be suspected if an individual has insulin level over $70 \mu \mathrm{U} / \mathrm{mL}$ at fasting or greater than $350 \mu \mathrm{U} / \mathrm{mL}$ post-OGTT. Some evaluate insulin resistance state indirectly by measuring the index of insulin sensitivity (Si). $\mathrm{Si}$ is the fractional clearance rate of glucose per unit change in the plasma insulin concentration. However, the gold standard technique to assess insulin resistance is to measure insulin mediated glucose disposal $(M)$ rate by the euglycemic hyperinsulinemic clamp [4]. By these methods, an individual with severe insulin resistance typically has $\mathrm{Si}$ of below $2 \mu \mathrm{U} / \mathrm{mL} / \mathrm{min} \times 10^{-6}$ and $M$ of less than $2 \mathrm{mg} / \mathrm{kg} / \mathrm{min}$ whereas a normal individual shows $\mathrm{Si}$ of above $5 \mu \mathrm{U} / \mathrm{mL} / \mathrm{min}$ $\times 10^{-6}$ and $M$ of above $6 \mathrm{mg} / \mathrm{kg} / \mathrm{min}$ [5].

3.2. Conditions Associated with Insulin Resistance. Several pathophysiological conditions and clinical syndromes are known to cause extreme insulin resistance. Those conditions and their clinical characteristic are summarized in Table 2. Insulin action is mediated through the phosphorylation of several key intermediate proteins when tyrosine kinase at $\beta$ subunit of insulin receptor is phosphorylated. Phosphorylation of tyrosine kinase occurs when insulin binds to the $\alpha$-subunit of insulin receptor. The mechanisms of insulin resistance include defects in insulin receptors due to genetic defect or insulin receptor antibodies, interference with intracellular insulin action due to the excess of counter-regulatory hormones or inflammatory cytokines, and increased insulin clearance.

Type A syndrome is characterized by hyperglycemia, hyperinsulinemia, acanthosis nigricans, and hyperandrogenism. It is generally due to a genetic defect either at the receptor level or in intermediate proteins involved in intracellular signaling steps of insulin action. It is seen predominately in females. The age of presentation is usually adulthood but if severe, for example, Rabson-Mendenhall or Leprechaunism, it can appear in neonates $[2,5]$. 
TABLE 1: Results of relevant laboratory work up.

\begin{tabular}{|c|c|}
\hline \multicolumn{2}{|l|}{ Admission lab } \\
\hline Hemoglobin A1c & $8.8 \%$ \\
\hline Lipid profile & $\begin{array}{l}\mathrm{LDL} 90 \mathrm{mg} / \mathrm{dL}(\mathrm{ref}<100 \mathrm{mg} / \mathrm{dL}) \\
\text { Triglycerides } 281 \mathrm{mg} / \mathrm{dL}(\mathrm{ref}<250 \mathrm{mg} / \mathrm{dL})\end{array}$ \\
\hline $\mathrm{CBC}$ & No leucopenia with normal differential count. mild normocytic anemia \\
\hline \multicolumn{2}{|l|}{ Autoimmune work up } \\
\hline ANA & Negative \\
\hline $\mathrm{pANCA} / \mathrm{cANCA}$ & Negative \\
\hline Complement levels & Normal \\
\hline ESR & 55 \\
\hline ds DNA & $1(\mathrm{ref}<4 \mathrm{IU} / \mathrm{mL})$ \\
\hline \multicolumn{2}{|l|}{ Others } \\
\hline Insulin ${ }^{*}$ & $34(\mathrm{ref}<17 \mu \mathrm{IU} / \mathrm{mL})$ \\
\hline C-peptide ${ }^{\wedge}$ & $2.62(\operatorname{ref} 0.8-3.1 \mathrm{ng} / \mathrm{mL})$ \\
\hline Glucagon & $283(\mathrm{ref}<134 \mathrm{pg} / \mathrm{mL})$ \\
\hline Anti-GAD (Glutamic Acid Decarboxylase) & $<1($ ref $<1)$ \\
\hline Insulin autoantibody & $>50(\mathrm{ref}<0.4 \mathrm{U} / \mathrm{mL})$ \\
\hline $24 \mathrm{hr}$ urine free cortisol & $66($ ref $4-50 \mathrm{mcg} / 24 \mathrm{~h})$ \\
\hline Plasma metanephrine & $<25(\mathrm{ref} \leq 57 \mathrm{pg} / \mathrm{mL})$ \\
\hline Plasma normetanephrine & $99(\mathrm{ref} \leq 148 \mathrm{pg} / \mathrm{mL})$ \\
\hline Plasma total metanephrines & $99(\mathrm{ref} \leq 205 \mathrm{pg} / \mathrm{mL})$ \\
\hline IGF-1 & $66($ ref $41-279$ ng/mL) \\
\hline TSH & $1.12(\operatorname{ref} 0.73-4.6 \mathrm{mIU} / \mathrm{mL})$ \\
\hline SPEP (serum protein electrophoresis) & No monoclonal spike \\
\hline
\end{tabular}

Additional comments

Lowest $\mathrm{pH}$ was 7.24 with serum bicarbonate level of $8 \mathrm{mmol} / \mathrm{L}$

and anion gap of 22 on day 4

Highest BUN and creatinine were $74 \mathrm{mg} / \mathrm{dL}$ and $3.7 \mathrm{mg} / \mathrm{dL}$

respectively on day 5

Highest BNP was $2047 \mathrm{pg} / \mathrm{mL}$ on day 5

Insulin level obtained on day 4 with corresponding glucose level at $749 \mathrm{mg} / \mathrm{dL}$ and insulin infusion rate at $32 \mathrm{units} / \mathrm{hr}$.

${ }^{\wedge} \mathrm{C}$-peptide level obtained on day 8 with corresponding glucose level at $108 \mathrm{mg} / \mathrm{dL}$.

Type B syndrome is insulin resistance mediated by antiinsulin receptor antibodies. It commonly presents at middle age. It is more commonly seen in females and African Americans. It is commonly associated with other autoimmune diseases such as vitiligo, alopecia areata, arthritis, nephritis, Hashimoto's thyroiditis, and primary biliary cirrhosis. SLE is the most commonly associated autoimmune disease. Type B syndrome can be associated with certain malignancies such as multiple myeloma, Hodgkin's disease and ataxia telangiectasia $[2,5,6]$.

Type $C$ syndrome is also known as HAIR-AN (hyperandrogenism, insulin resistance, and acanthosis nigricans) [5]. This syndrome is phenotypically similar to Type A but these patients are obese. It is found in 5\% of patients with PCOS. The etiology is unknown but is not due to mutation in insulin receptor gene [3].

Hypersensitivity syndrome refers to the clinical situation where insulin resistance develops from insulin antibodies (IAs). Antibodies to exogenous insulin rarely have clinical significance as those antibodies have a low binding capacity. They bind with high affinity and do not readily separate. However, Ishizuka et al. report two cases of IA-mediated insulin resistance. In both cases, IA developed in two elderly insulin dependent patients, years after switching human insulin to analog insulin. They both presented with severe daytime hyperglycemia due to the binding of IA to insulin and early morning hypoglycemia due to the separation of antibodies from insulin. Unlike the common IA seen in patients on exogenous insulin, the insulin antibodies measured in those patients were demonstrated to have much lower affinity and higher capacity than antibodies found in insulin autoimmune syndrome (IAS) [7] .

3.3. Approach to Patients with Insulin Resistance. A case of insulin resistance can be approached in 3 steps: achieving good glycemic control, establishing diagnosis, and treating underlying etiology. In term of glycemic control, avoiding 
TABLE 2: Conditions associated with insulin resistance [2, 3, 5, 8-14].

\begin{tabular}{ll}
\hline & Characteristics/clinical features \\
\hline Type A syndrome & $\begin{array}{l}\text { Insulin receptor gene mutations or IRS-1 mutation or defect in other signaling } \\
\text { intermediates/GLUT }\end{array}$ \\
$\begin{array}{l}\text { Type B syndrome } \\
\text { Type C syndrome (HAIR-AN) } \\
\text { Lipodystrophy }\end{array}$ & $\begin{array}{l}\text { Hyperandrogenism, insulin resistance, and acanthosis nigricans } \\
\text { Congenital or acquired (HIV lipodystrophy) }\end{array}$ \\
Excess of counter-regulatory hormones or & $\begin{array}{l}\text { Acromegaly, glucagonoma, Cushing's syndrome } \\
\text { endocrine disorders }\end{array}$ \\
& Phecochromocytoma, thyrotoxicosis \\
& Insulinoma or hyperinsulinemic states \\
Pathophysiological states & Puberty, pregnancy, and advanced age \\
& Obesity, metabolic syndrome, cirrhosis, MI, and ketoacidosis \\
Others & Uremia, sepsis \\
Pseudoinsulin resistance & \\
Hypersensitivity (anti-insulin antibodies) & Auman or technical errors \\
Subcutaneous insulin resistance (SIR) & Increased insulin degrading activity in sub-Q tissue \\
Increased insulin clearance & Increased degradation of insulin in the circulation \\
Medications & Niacin, steroid, IFN-alpha, atypical antipsychotics, PI, and NRTI
\end{tabular}

IRS: insulin receptor substrate; GLUT: glucose transporter; HIV: human immunodeficiency virus; MI: myocardial infarction; sub-Q: subcutaneous; IFN: interferon; PI: protease inhibitor; NRTI: nucleoside reverse transcriptase inhibitor.

hypoglycemia is equally important as preventing complication related to hyperglycemia. Monitoring and managing patients in ICU with IV insulin infusion by trained staff is essential and the safest therapeutic modality. IV insulin should be continued until the patient's clinical condition is improved and precipitating factors are resolved. Insulin resistance in the hospitalized patient is often multifactorial and one should rule out pseudo-resistance to insulin, a condition due to human or technical errors before investigating rare etiologies. The general approach to establish the underlying cause of insulin resistance in a hospitalized patient is outlined in Figure 2.

Once the diagnosis is established, specific treatment targeting the underlying mechanism should be started along with glycemic control. Insulin resistance due to type B syndrome and insulin antibodies is reported to respond to immunosuppressants and steroids in case series studies $[6,7]$.

\section{Case Discussion}

This is a case of a 60-year-old centrally obese Hispanic man with MI, DKA, acute renal failure, and extreme insulin resistance which was unpredictable and varied day to day for the first 22 days of hospitalization. Interestingly, insulin resistance resolved after CABG.

Clinically our patient did not have features of Type C or lipodystrophy. He did not have clinical or biochemical evidence of thyrotoxicosis, pheochromocytoma, or underlying autoimmune diseases. His glucagon level was mildly elevated consistent with his renal insufficiency. It was well below values seen in glucagonoma (typically $>500 \mathrm{pg} / \mathrm{mL}$ ).

It is well recognized that pathophysiological stress in DKA and MI causes insulin resistance by increasing catecholamines and cortisol through the activation of the sympathetic nervous system and hypothalamic-pituitaryadrenal axis, respectively. In addition, the upregulation of proinflammatory cytokines such as IL- 6 and TNF- $\alpha$ interferes with insulin signal transduction through the activation of serine kinase instead of tyrosine kinase and creates insulin resistance $[15,16]$.

Yokoyama et al. describe a case of extreme insulin resistance requiring 90,000 units of insulin over 24 hour in a long standing type 2 diabetic patient who presented with DKA and cardiogenic shock. In that case, the transiently low $\mathrm{pH}$ was not demonstrated to have a significant effect on insulin binding, activity, or rate of insulin degradation [1]. Insulin autoantibodies and insulin receptor antibodies were not detected, and an exact mechanism of insulin resistance could not be determined. In Yokoyama's case, the course of insulin resistance was not as prolonged as in our patient.

Though our patient did not show clinical evidence of recurrent ischemia, his insulin resistance resolved after CABG. The effect of clinically inapparent cellular oxidative injury on insulin action as described in the animal models by Ohta et al. could explain extreme insulin resistance in the setting of MI patients. In their study with MI and control mice, Ohta et al. demonstrated that phosphorylation of Akt (a major intermediate protein involved in insulin metabolic pathway) and translocations of GLUT 4 were remarkably reduced in skeletal muscle of MI mice (61\% and $23 \%$ respectively). The defects were corrected by eliminating hypoxemia by treating skeletal muscle of MI mice with apocynin, an inhibitor of $\mathrm{NAD}(\mathrm{P}) \mathrm{H}$ oxidase [17].

In addition, previous studies on patients with MI demonstrated that adiponectin levels varied during the course and recovery of MI. The rate and level of adiponectin rise were noted to be slower and lesser in diabetic patients than 


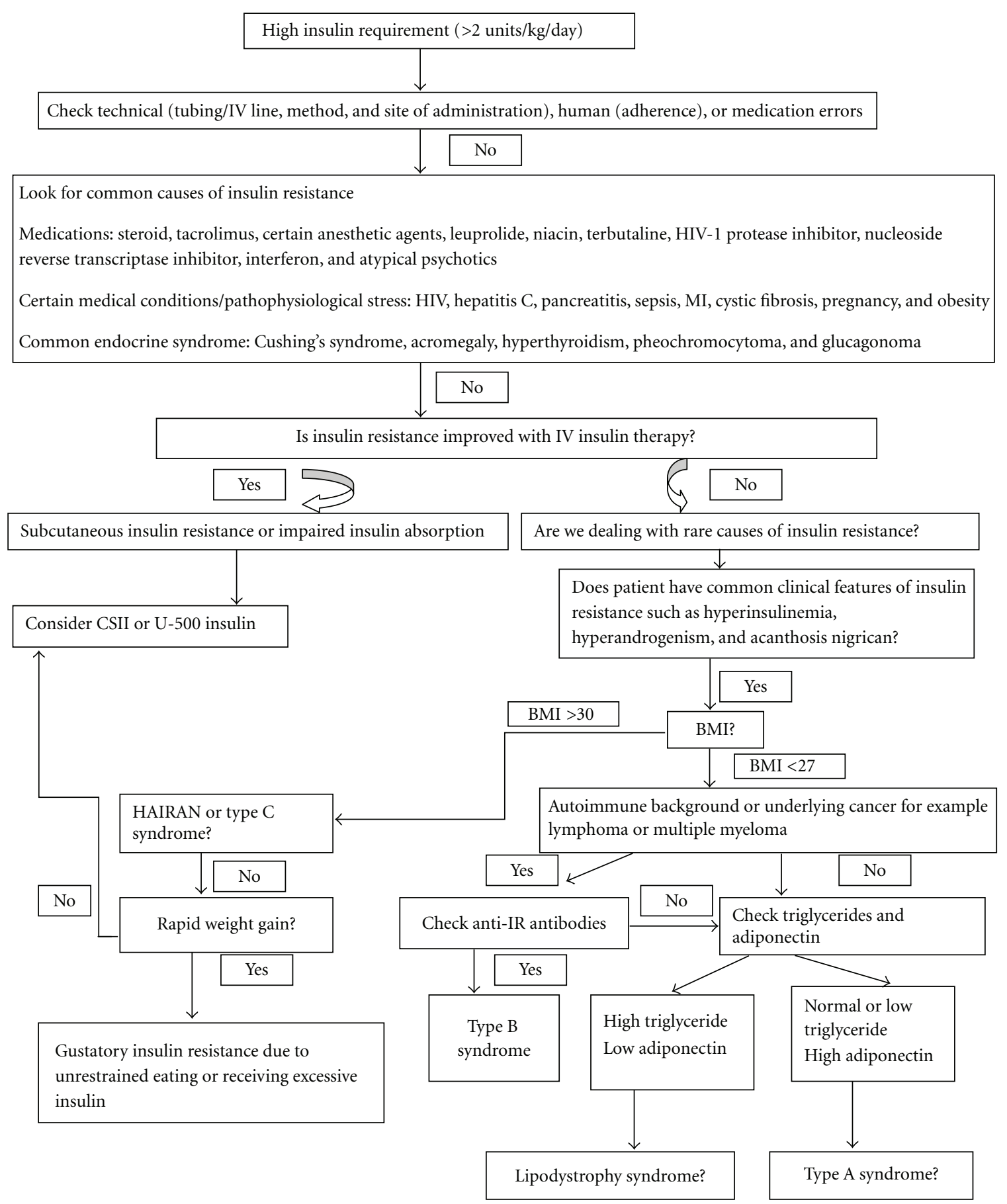

FIGURE 2: Outline of a general approach to a patient with insulin resistance (modified from Ovalle F. Diabetes Res Clin Pract. December 2010; 90(3): 231-42) [3].

non-diabetic patients [18]. This may contribute to the more pronounced insulin resistance seen in diabetic patients, due to the lack of adiponectin's insulin sensitizing effect. Per Eyileten et al., adiponectin level in atherosclerotic patients was noted to be significantly lower than control (mean adiponectin level $7.02 \pm 2.01$ versus $25.46 \pm 3.91 \mu \mathrm{g} / \mathrm{mL}$, $P$ value $<0.001)$ which could contribute to significantly higher HOMA-IR $(1.86 \pm 0.3$ versus $1.26 \pm 0.33, P$ value $<$ 0.001). CABG ameliorates the decreased adiponectin level
(pre-CABG versus post-CABG was $7.02 \pm 2.01$ versus $8.67 \pm$ $2.05 \mu \mathrm{g} / \mathrm{mL}, P$ value $<0.001)$ and improved HOMA-IR $(1.86 \pm$ 0.3 versus $1.59 \pm 0.33, P$ value $<0.001)$ in atherosclerotic patients [19]. However, the actual effect of adiponectin in the development of insulin resistance in MI needs further confirmational study.

Though anti-GAD was negative in our patient, insulin autoantibodies were measurable. The development of insulin resistance by insulin autoantibodies has been reported in the 
Japanese literature particularly in patients who are switched to analog insulin from human insulin [7]. These antibodies are demonstrated to have high binding capacity but low affinity for insulin mimicking characteristic of autoantibodies found in a patient with insulin autoimmune syndrome (IAS). Patients usually display a pattern of early morning hypoglycemia and daytime hyperglycemia because the separation of antibodies from insulin usually happens in the morning while binding of antibodies to insulin occurs during daytime $[7,14]$. The binding capacity and affinity of insulin autoantibodies can be determined by scatchard analysis as described in Matsuyoshi et al. [20]. The potential role of insulin autoantibodies in causing our patient's insulin resistance was not determined, as scatchard analysis was not commercially available. However, we do not believe that his insulin resistance was caused by insulin autoantibodies. Treatment of insulin resistance caused by insulin autoantibodies with high capacity and low affinity requires immunosuppressants or steroids [7], which our patient did not receive. In addition, our patient did not show a pattern typically seen in a patient with insulin resistance due to insulin autoantibodies such as early morning hypoglycemia and daytime hyperglycemia.

Insulin receptor antibodies were not measured in our case but we do not believe they played a role because of the absence of clinical features of an autoimmune disease or malignancy [6]. In addition, his insulin resistance resolved after CABG without receiving immunosuppressant or steroid therapy.

Although the initial anion gap was closed on day 2, the patient developed more severe DKA and hyperglycemia after switching to subcutaneous insulin from intravenous (IV) insulin. Thus, a premature switch to subcutaneous insulin and hyperglycemia (glucose toxicity) can be considered as the additional contributing factors to his unusually prolonged course of insulin resistance. Based on our experience with this case, IV insulin should be continued until the severe hyperglycemia resolves and the patient's clinical condition improves and stabilizes. In fact, IV insulin is the safest measure in cases such as ours, as his insulin requirements were unpredictable and varied. Hence, institution-driven IV insulin protocols, with guidelines on how to handle unusual insulin requirements, should be established to avoid extreme hyperglycemia and hypoglycemia.

His measured insulin level was inappropriately low while he was receiving high dose of insulin subcutaneously as well as IV (infusion and IV push). He appears, therefore, to have increased insulin clearance. The mechanism is unclear, but increased clearance may have played a role in his high insulin requirements.

\section{Conclusion}

Though pseudoinsulin resistances due to human or technical error is a common cause of apparently high insulin needs, our patient showed an unusually prolonged course of insulin resistance even after we thoroughly examined and ruled out those factors.

The exact mechanism of the development of extreme insulin resistance in DKA and MI is still unknown. However, we believe it is not solely due to the excess of counterregulatory hormones or inflammatory cytokines.

The etiology of transient extreme insulin resistance in our case is likely to be multifactorial: for example, pathophysiological stress (DKA, MI, uremia, and CHF), early inappropriate switch of insulin from IV to subcutaneous while absorption was unpredictable due to edema or impaired peripheral circulation resulted in prolonged hyperglycemia and glucose toxicity and finally possible role of increased insulin clearance. The role of low $\mathrm{pH}$ and cellular oxidative stress on the function of pancreas, insulin action, and metabolism in DKA and MI and the clinical significance of insulin autoantibodies in the development of insulin resistance require further study.

\section{References}

[1] H. Yokoyama, T. Wasada, Y. Shimizu, H. Yoshino, S. Hasumi, and Y. Omori, "Transient extreme insulin resistance in shock during diabetic ketoacidosis," Endocrinologia Japonica, vol. 39, no. 6, pp. 571-576, 1992.

[2] C. S. Mantzoros and J. S. Flier, "Insulin resistance: the clinical spectrum," Advances in Endocrinology and Metabolism, vol. 6, pp. 193-232, 1995.

[3] F. Ovalle, "Clinical approach to the patient with diabetes mellitus and very high insulin requirements," Diabetes Research and Clinical Practice, vol. 90, no. 3, pp. 231-242, 2010.

[4] R. N. Bergman, R. Prager, A. Volund, and J. M. Olefsky, "Equivalence of the insulin sensitivity index in man derived by the minimal model method and the euglycemic glucose clamp," The Journal of Clinical Investigation, vol. 79, no. 3, pp. 790-800, 1987.

[5] A. Vidal-Puig and D. E. Moller, "Insulin resistance: classification, prevalence, clinical manifestations and diagnosis," in Androgen Excess Disorders in Women, pp. 227-236, Lippincott Raven, 1997.

[6] R. Malek, A. Y. Chong, B. C. Lupsa et al., "Treatment of type B insulin resistance: a novel approach to reduce insulin receptor autoantibodies," The Journal of Clinical Endocrinology \& Metabolism, vol. 95, no. 8, pp. 3641-3647, 2010.

[7] T. Ishizuka, S. Ogawa, T. Mori et al., "Characteristics of the antibodies of two patients who developed daytime hyperglycemia and morning hypoglycemia because of insulin antibodies," Diabetes Research and Clinical Practice, vol. 84, no. 2, pp. e21-e23, 2009.

[8] C. R. Kahn, J. S. Flier, R. S. Bar et al., "The syndromes of insulin resistance and acanthosis nigricans. Insulin receptor disorders in man," The New England Journal of Medicine, vol. 294, no. 14, pp. 739-745, 1976.

[9] E. P. Paulsen, J. W. Courtney III, and W. C. Duckworth, "Insulin resistance caused by massive degradation of subcutaneous insulin," Diabetes, vol. 28, no. 7, pp. 640-645, 1979.

[10] G. Williams, J. C. Pickup, and H. Keen, "Massive insulin resistance apparently due to rapid clearance of circulating insulin," The American Journal of Medicine, vol. 82, no. 6, pp. 1247-1252, 1987.

[11] J. Kusari, Y. Takata, E. Hatada, G. Freidenberg, O. Kolterman, and J. M. Olefsky, "Insulin resistance and diabetes due to different mutations in the tyrosine kinase domain of both insulin receptor gene alleles," The Journal of Biological Chemistry, vol. 266, no. 8, pp. 5260-5267, 1991. 
[12] S. R. Hager, "Insulin resistance of uremia," American Journal of Kidney Diseases, vol. 14, no. 4, pp. 272-276, 1989.

[13] G. F. Lewis, A. Carpentier, K. Adeli, and A. Giacca, "Disordered fat storage and mobilization in the pathogenesis of insulin resistance and type 2 diabetes," Endocrine Reviews, vol. 23, no. 2, pp. 201-229, 2002.

[14] S. I. Taylor, F. Barbetti, D. Accili, J. Roth, and P. Gorden, "Syndromes of autoimmunity and hypoglycemia. Autoantibodies directed against insulin and its receptor," Endocrinology and Metabolism Clinics of North America, vol. 18, no. 1, pp. 123-143, 1989.

[15] G. S. Hotamisligil, "Inflammation and metabolic disorders," Nature, vol. 444, no. 7121, pp. 860-867, 2006.

[16] Y. Y. Wang, S. Y. Lin, Y. H. Chuang, C. J. Chen, K. C. Tung, and W. H. H. Sheu, "Adipose proinflammatory cytokine expression through sympathetic system is associated with hyperglycemia and insulin resistance in a rat ischemic stroke model," American Journal of Physiology, vol. 300, no. 1, pp. E155-E163, 2011.

[17] Y. Ohta, S. Kinugawa, S. Matsushima et al., "Oxidative stress impairs insulin signal in skeletal muscle and causes insulin resistance in postinfarct heart failure," American Journal of Physiology, vol. 300, no. 5, pp. H1637-H1644, 2011.

[18] P. Krasnodębski, G. Opolski, and W. Karnafel, "Plasma adiponectin levels in acute myocardial infarction and during the postinfarction recovery period in patients with type 2 diabetes mellitus," Kardiologia Polska, vol. 69, no. 9, pp. 924-930, 2011.

[19] Z. Eyileten, M. I. Yilmaz, K. Kaya et al., "Coronary artery bypass grafting ameliorates the decreased plasma adiponectin level in atherosclerotic patients," Tohoku Journal of Experimental Medicine, vol. 213, no. 1, pp. 71-77, 2007.

[20] A. Matsuyoshi, S. Shimoda, K. Tsuruzoe et al., "A case of slowly progressive type 1 diabetes with unstable glycemic control caused by unusual insulin antibody and successfully treated with steroid therapy," Diabetes Research and Clinical Practice, vol. 72, no. 3, pp. 238-243, 2006. 


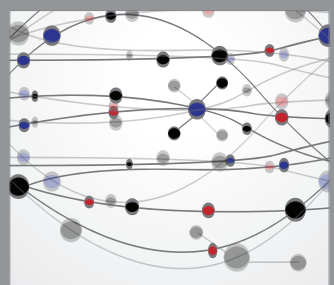

The Scientific World Journal
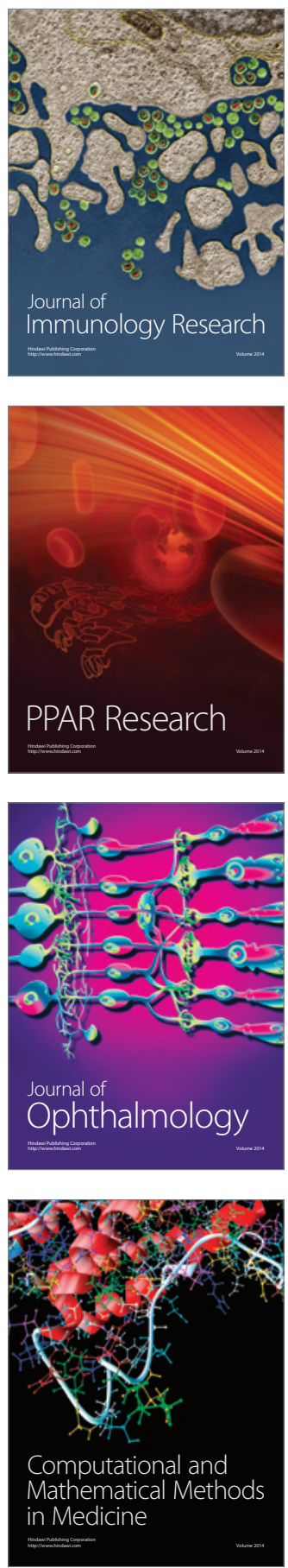

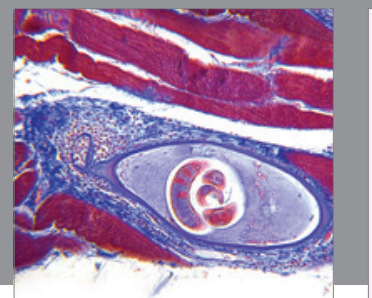

Gastroenterology

Research and Practice
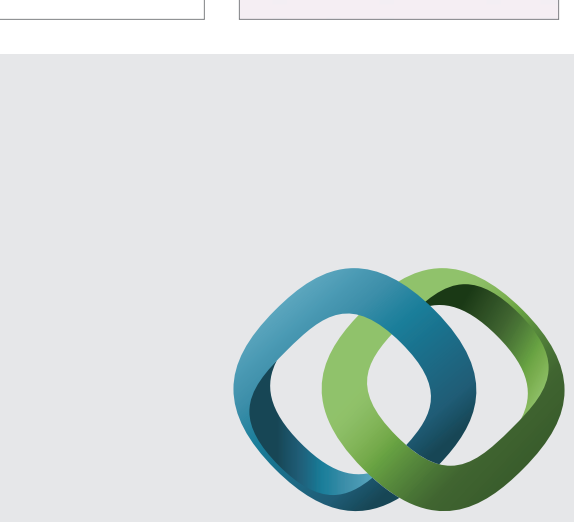

\section{Hindawi}

Submit your manuscripts at

http://www.hindawi.com
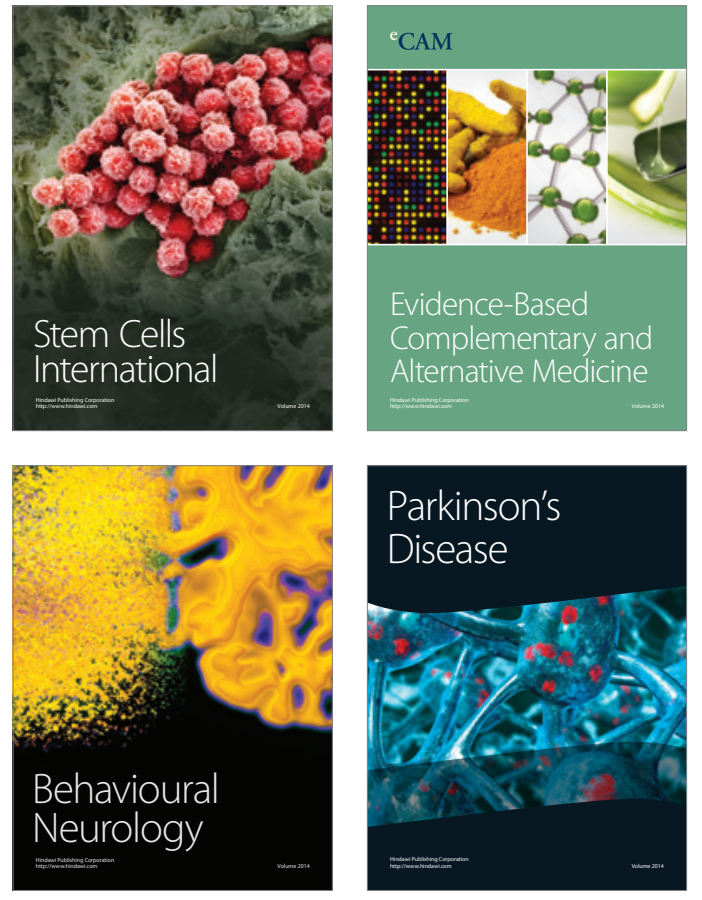
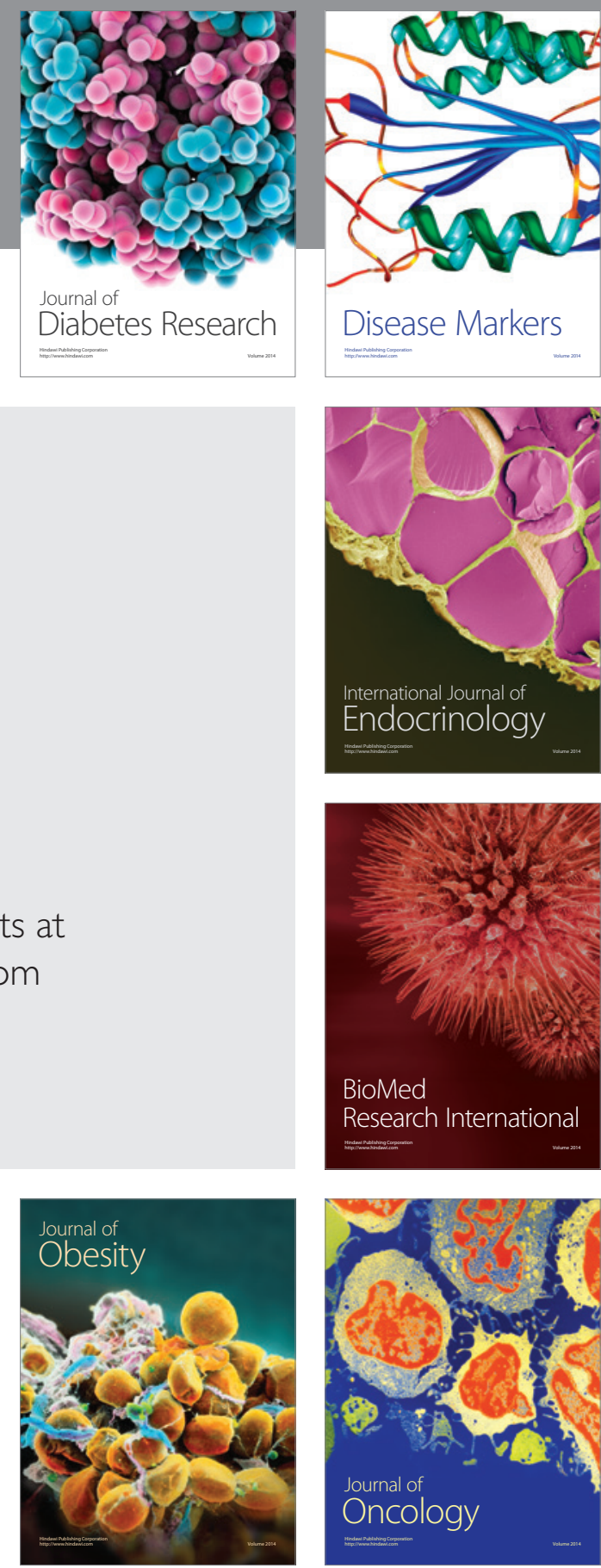

Disease Markers
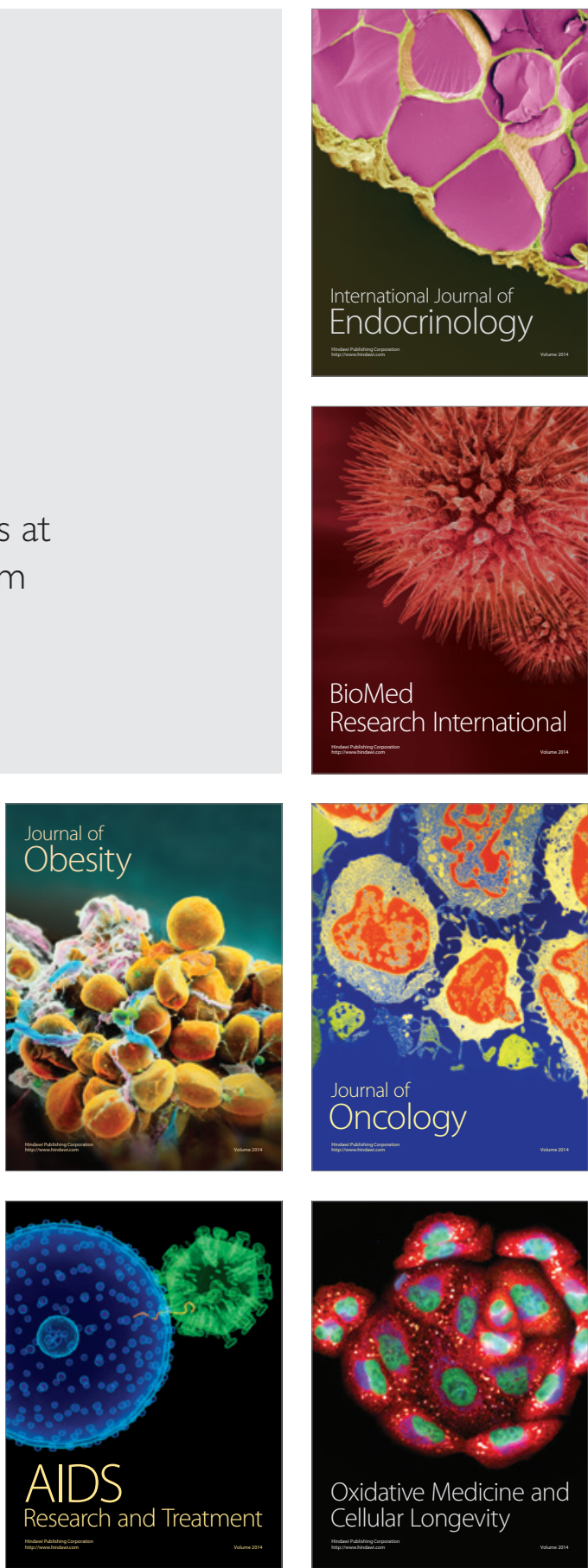